\title{
Effect of Core Stability Training on Static and Dynamic Balance and Strength in Disabled Veterans with Unilateral Below Knee Amputation
}

\section{ART ICLE INF O}

\section{Article Type}

Original Research

\section{Authors}

Ghassemi S.A. ${ }^{* 1} M S C$

Rahnama N. ${ }^{2} P h D$

Daneshmandi H. ${ }^{3} M D$

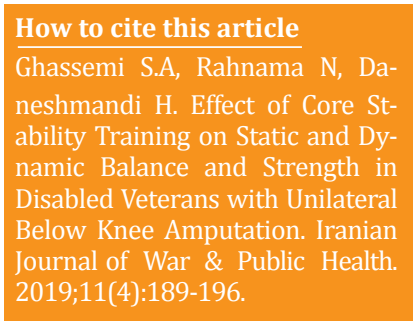

${ }^{1}$ Sport Injuries \& Corrective ExercisesDepartment, Physical Education \& Sport Sciences Faculty, Kish International Campus, University of Tehran, Kish, Iran

${ }^{2}$ Sport Injuries \& Corrective ExercisesDepartment, Physical Education \& Sport Sciences Faculty, University of Isfahan, Isfahan, Iran

${ }^{3}$ Sport Injuries \& Corrective ExercisesDepartment, Physical Education \& Sport Sciences Faculty, University of Guilan, Guilan, Iran

\section{*Correspondence}

Address: Kish International Campus, University of Tehran, Niyayesh Street, Mirmohana Boulevard Kish, Iran. Postal Code: 7941639982 Phone: +98 (51) 38810231

Fax: +98 (51) 35010430 sayyedalighassemi@yahoo.com

\section{Article History}

Received: December 31, 2018

Accepted: September 3, 2019

ePublished: December 21, 2019

\section{A B S T R A C T}

Aim(s) Individuals with lower extremity amputation have more difficulties than healthy people in static and dynamic balance. The significant effect of core stability training in different subjects has proven in previous studies. Therefore, the aim of this study was to investigate the effect of core stability training on static and dynamic balance and strength on disabled veterans with unilateral below knee amputation.

Materials \& Methods This semi-experimental study with pretest-posttest design and control group was carried out on 36 disabled veterans with unilateral below knee amputation in Mashhad city in 2018. The subjects were selected by the purposive sampling method and the subjects were randomly divided into two experimental and control groups $(\mathrm{N}=18)$. After measuring the static and dynamic balance and strength variables, core stability training was performed for the subjects of the experimental group for 8 weeks and 3 sessions per week under the supervision of the researcher. Then, the research variables were again evaluated in two groups. Data were analyzed through SPSS 19 software using independent and paired sample t-tests.

Findings There was a significant difference between the mean scores of post-test and pretest in the experimental group $(\mathrm{p}<0.0001)$, but there was no significant difference between the mean scores of the posttest and pretest in the control group ( $p>0.05)$. Also, there was a significant difference between the experimental and control groups in the post-test step $(\mathrm{p}<0.0001)$

Conclusion The offered training can be effective in the balance, strength and core stability in people with unilateral lower limb amputation and can improve their balance.

Keywords Strength; Postural Balance; Amputation; Lower Extremity

\section{I T A T I O N L I N K S}

[1] Rehabilitation of adult upper limb ... [2] Enhancement of a prosthetic knee with a ... [3] Fall-risk-increasing drugs: a systematic ... [4] Severity of sarcopenia is associated with postural ... [5] Fall incidence and associated risk factors among ... [6] Dual-task assessment of reorganization of ... [7] A water-based training ... [8] Reorganisation of postural control following ... [9] Greater fall risk in elderly women than ... [10] The influence of falling, fear of falling, and balance ... [11] A prospective study examining ... [12] A pilot study examining measures of balance ... [13] Use of a dynamic balance system ... [14] Control of lateral balance in walking ... [15] Postural sway and active balance ... [16] Balance control on a moving platform in ... [17] Gait rehabilitation for a patient with ... [18] The relationship between core ... [19] Core stability training: applications to sports ... [20] Core ... [21] The role of core stability in athletic ... [22] Validity of the Schultz Slam Test (SST) as a core ... [23] Effects of pilates-based core stability training in ... [24] Core stability and its relationship to lower ... [25] Effects of a program for trunk strength ... [26] Effects of Swiss-ball core strength training ... [27] Minimally invasive treatment for fractures of lower ... [28] Endurance times for low back ... [29] The Effect of aquatic and land-based ... [30] Core training: stabilizing the ... [31] Effect of core stability training on trunk ... [32] Core stability training in dynamic balance testing ... [33] The effect of core stability training ... [34] Core Stability Training Program (CSTP) effects ... [35] Effectiveness of core stability training and ... [36] The effect of eight weeks of core stability ... [37] Effect of six weeks of dura disc and ... [38] The effect of core stability training on balance ... [39] Relationship between isocapnic ... [40] The myth of core ... [41] The effects of stability ball training ... [42] Is there a relationship between core ... [43] Balance confidence among people ... [44] The effect of core stabilization training ... [45] Core strengthening and balance in the ... [46] Improvement in dynamic balance and core ... 
همجون اسكوليوز، هاييرلوردوز و هاييركايفوز و دفورميتىهاى لكَن

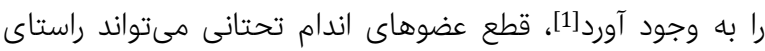

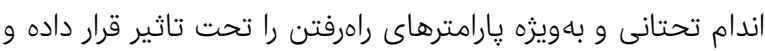

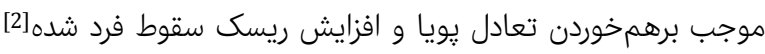

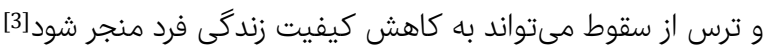

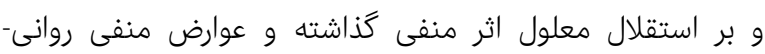
اجتماعى و جسمانى ديكرى را بهدنبال داشته باشد. تحقيقات نشان أنان

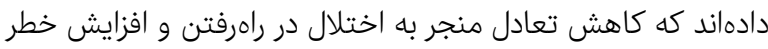

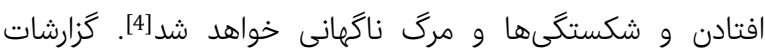

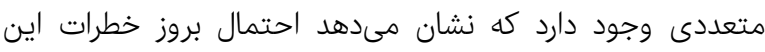

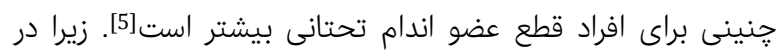

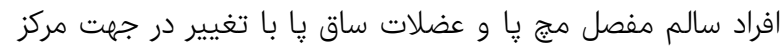

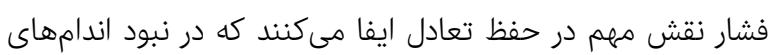

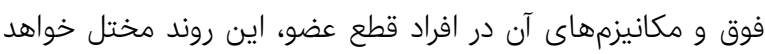

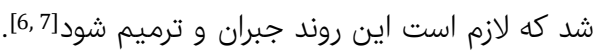

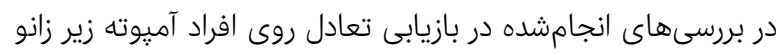

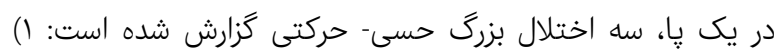

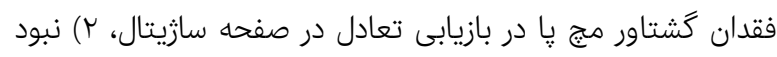

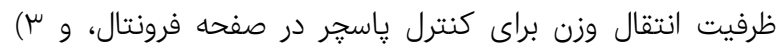

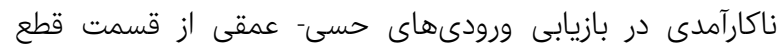

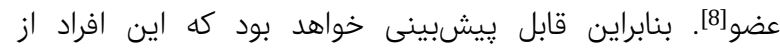

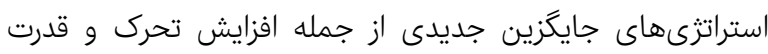

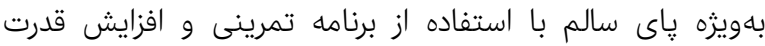
موضعى و عمومى بدن براى حفظ تعادل ايستا و يويا استفاده إنيا

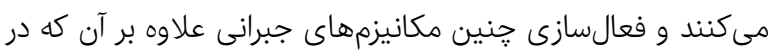

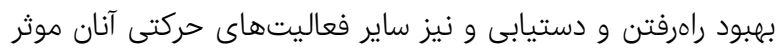

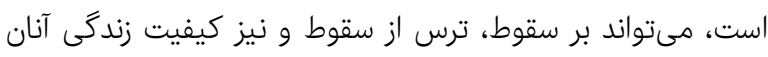

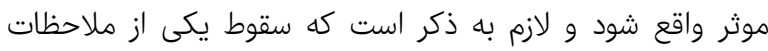

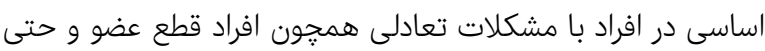

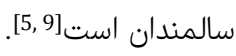

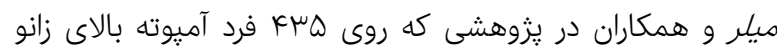

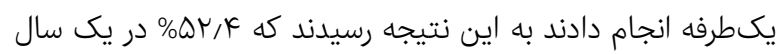

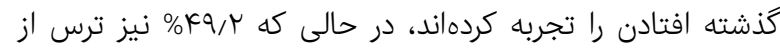

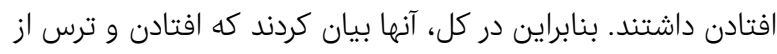

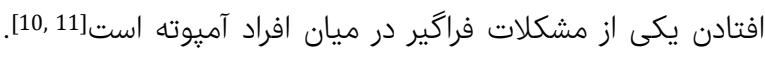

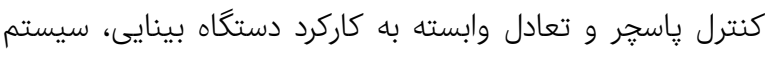

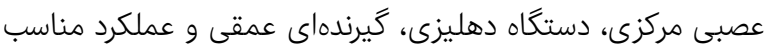

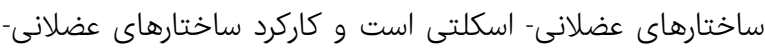

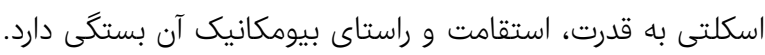

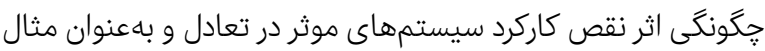

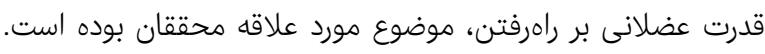

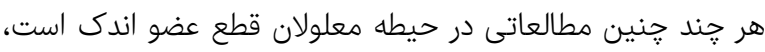

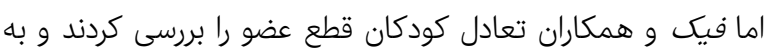
اين نتيجه رسيدند كه سرعت راهرفتن، مسافت و عملكرد تعادل در كران كران

\section{تاثير تمرينات ثبات مركزى بر تعادل ايستا و يويا و قدرت در جانبازان قطع عضو زير زانوى يكطرفه}

\author{
MSc "سيدعلى قاسمى
}

گروه آسيبشناسى ورزشى و حركات اصلاحى، دانشكده تربيت بدنى و علوم ورزشى، يرديس بينالملى كيش، دانشكاه تهران، كيش، ايران

نادر رهنما PhD

گروه آسيبشناسى ورزشى و حركات اصلاحى، دانشكده تربيت بدنى و علوم ورزشى، دانشگاه اصفهان، اصفهان، ايران

حسن دانشمندى PhD گروه آسيبشناسى ورزشى و حركات اصلاحى، دانشكده تربيت بدنى و علوم

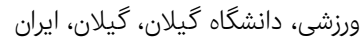

جكيده اهداف: افراد دجار قطع عضو اندام تحتانى مشكلات بيشترى نسبت به افراد سالم

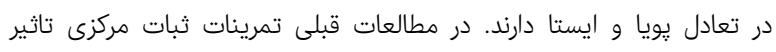

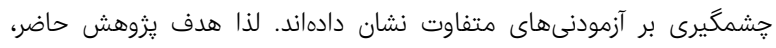

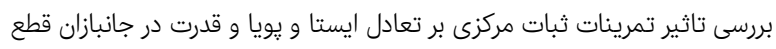
عضو زير زانوى يكىطرفه بود.

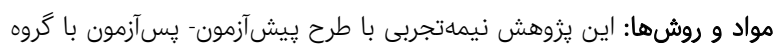

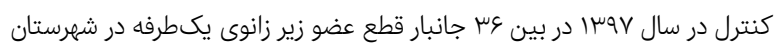

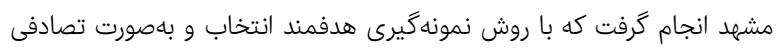

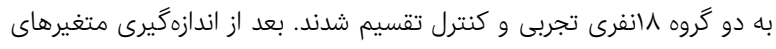

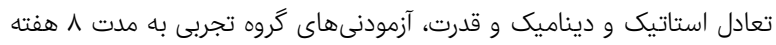

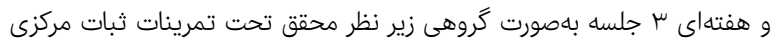

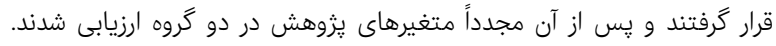

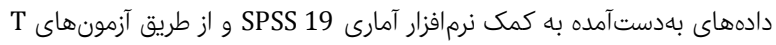
مستقل و T همبسته مورد تجزيه و تحليل قرار گرفتند.

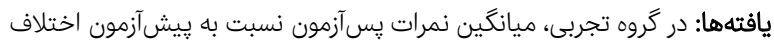

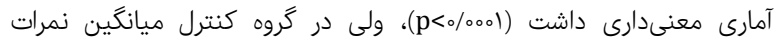

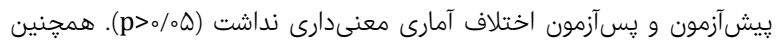

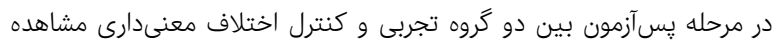
شد (p<o $)$ نتيجه گيرى: تمرينات ارايهشده مىتواند بر تعادل، قدرت و ثبات مركزى بدن در

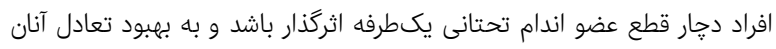

منجر شود. كليدوازهها: قدرت، تعادل، قطع عضو، اندام تحتانى

تاريخ دريافت: تاريخ

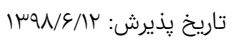

نويسنده مسئول: sayyedalighassemi@yahoo.com

\section{مقدمه}

عملكرد بهيينه فعاليتهاى حركتى نيازمند تعادل ايستا و يويا است.

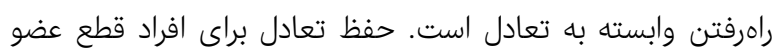

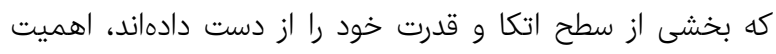

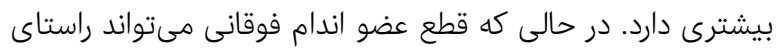
ستون فقرات را بر هم زده و ناهنجارىهاى عضلانى- اسكلتى 


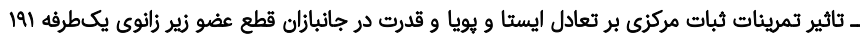

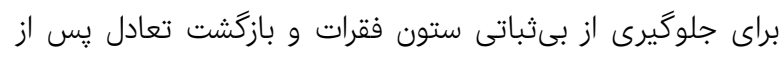

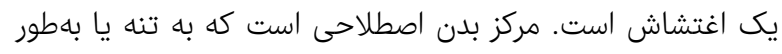

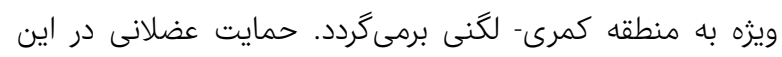

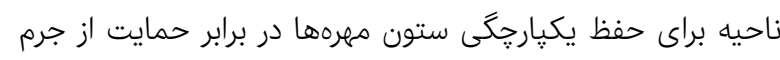

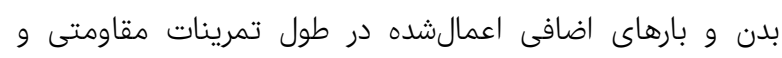

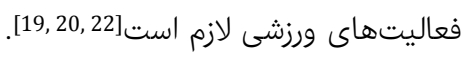

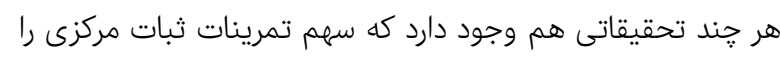

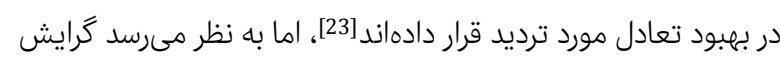

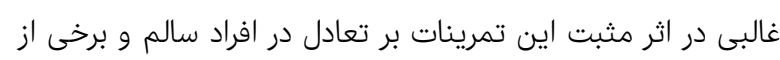

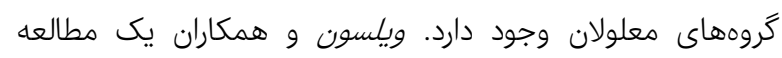

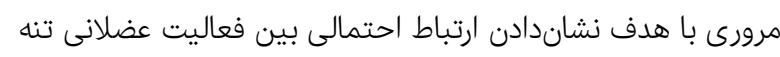

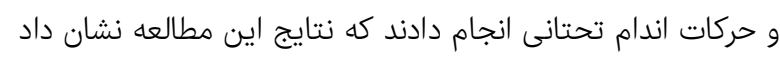

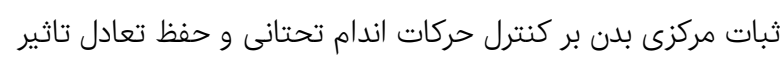

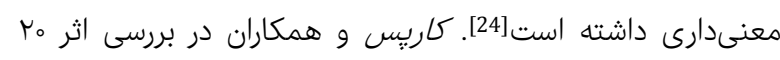

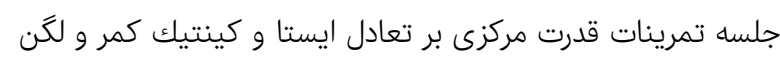

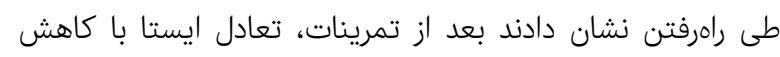

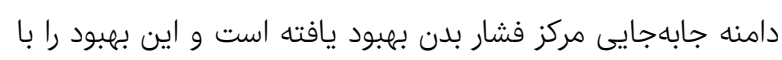

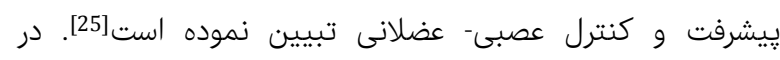

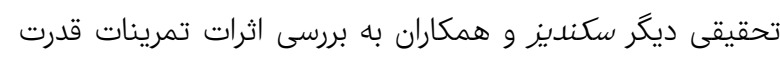

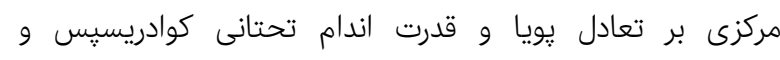

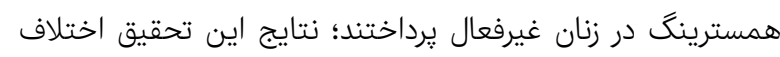

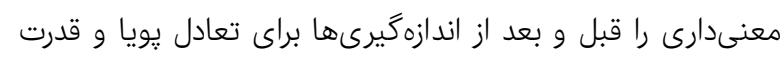

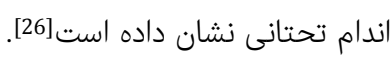

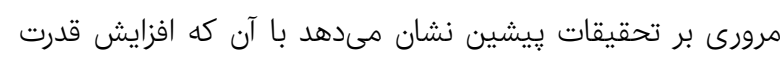

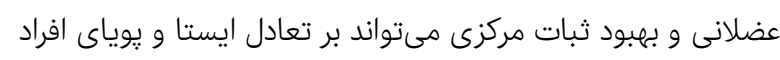

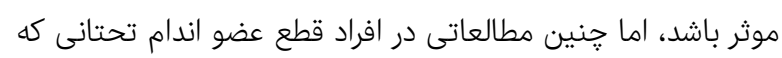

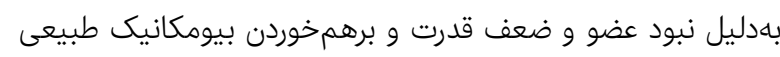

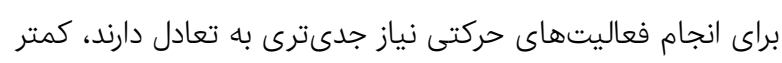

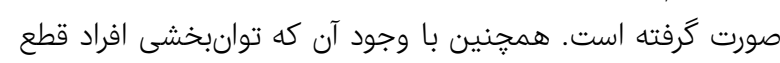

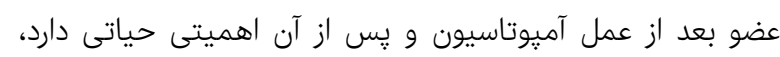

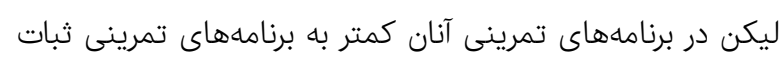

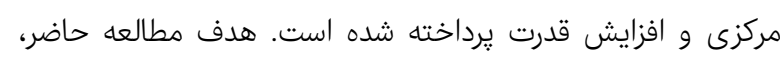

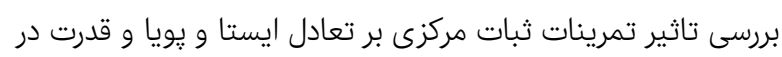

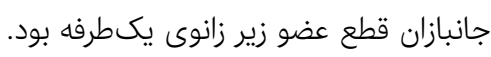

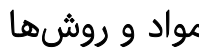

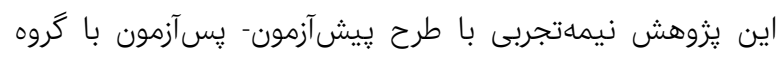

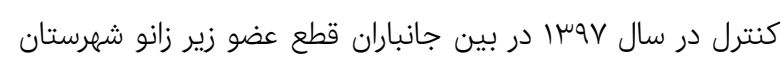

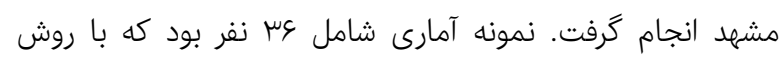

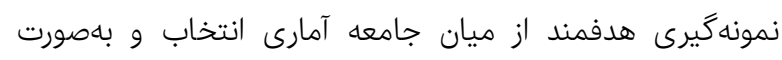

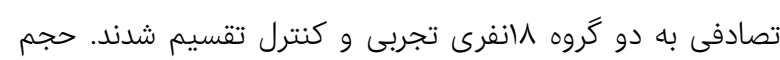

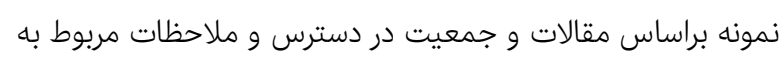

همسانسازى نمونه تعيين شد [27]. مركز اجراى تحقيق مركز ارتز و بروتز جانبازان مشهد و محل آنمون
اين كودكان بلهورت معنىدارى كمتر از كودكان سالم است[12] كأ.

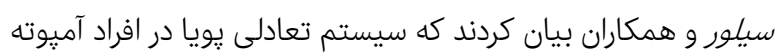

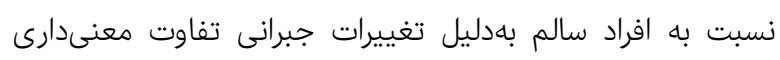

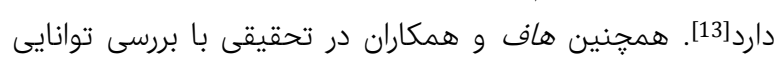

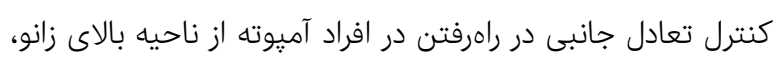

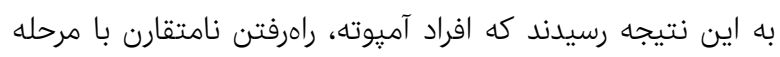

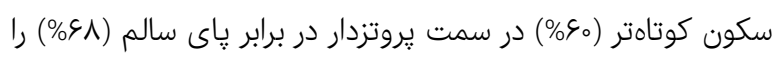

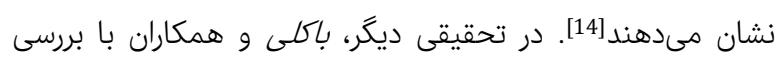

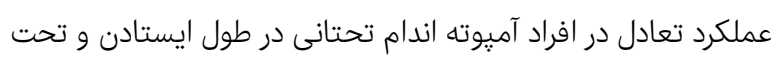

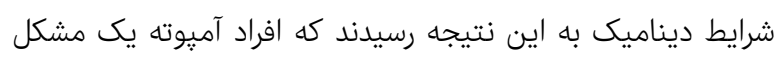

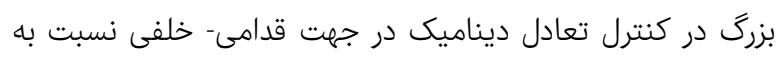
جهت داخلى - جانبى دارند [15].

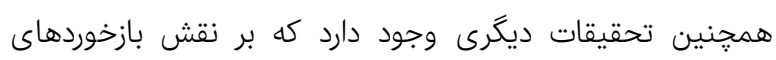

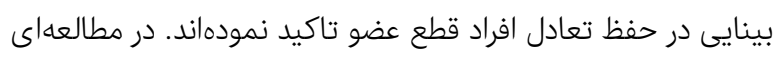

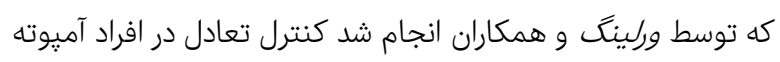

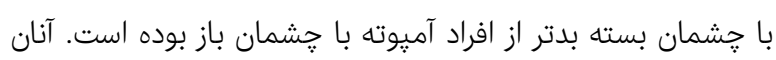

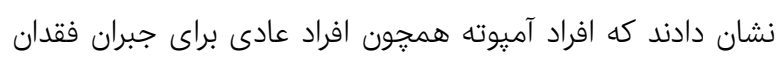

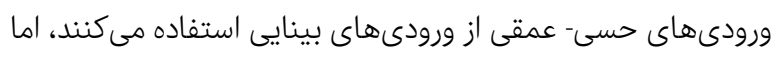

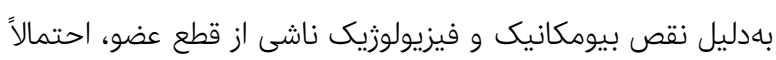

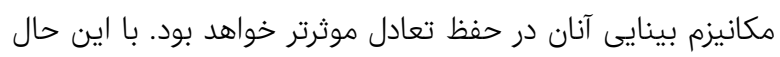

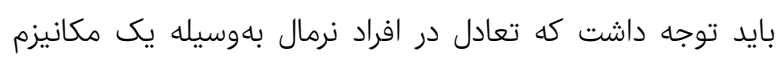

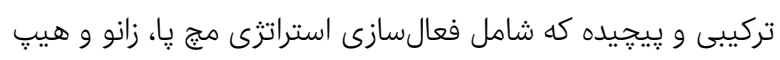

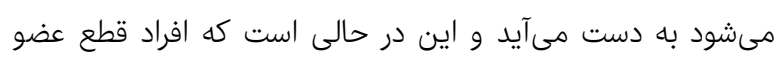

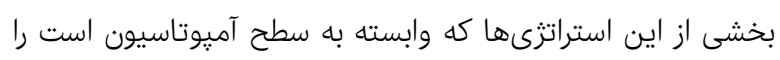

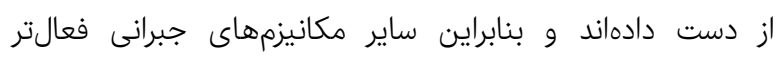

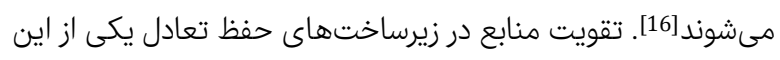

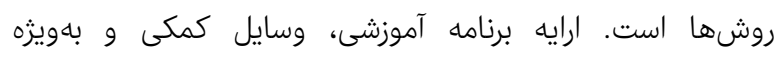

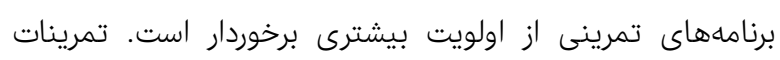

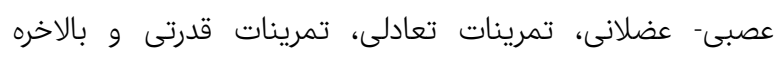

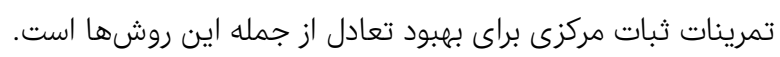

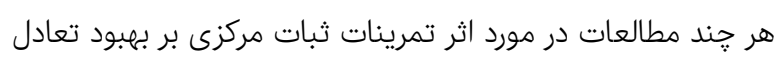

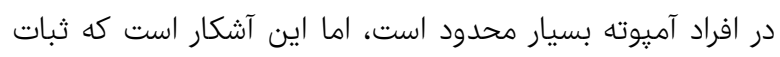

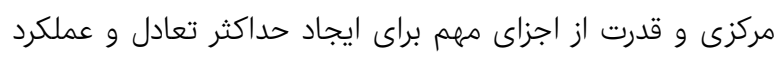

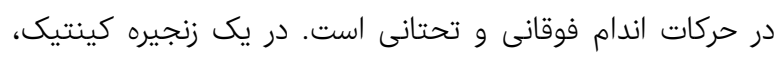

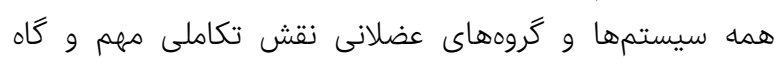

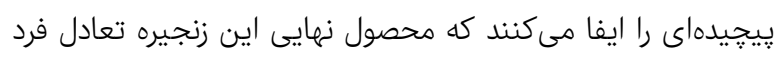

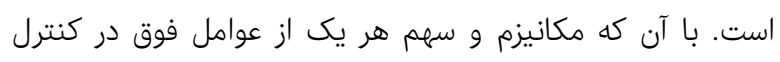

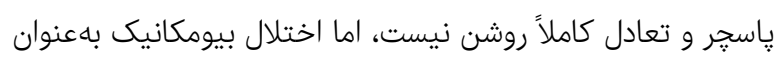

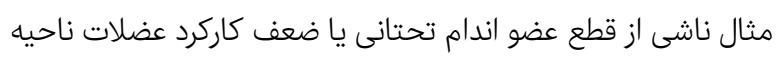

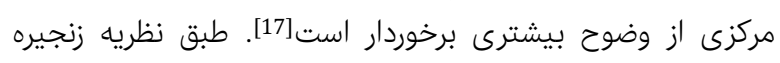

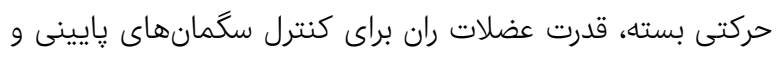

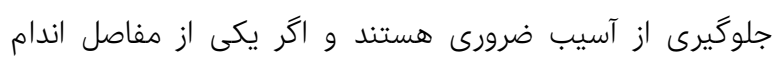

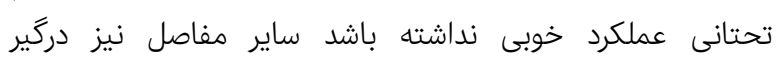
مىشوند[18-21]. ثبات مركزى قابليت مجموعه كمرى- لكَنى- رانى ندئ دركير 


\begin{tabular}{|c|c|}
\hline & مه تمرينى ثبات مركزى \\
\hline تعداد ستها و تكرارها & نوع تمرينات \\
\hline 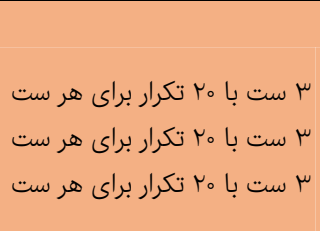 & 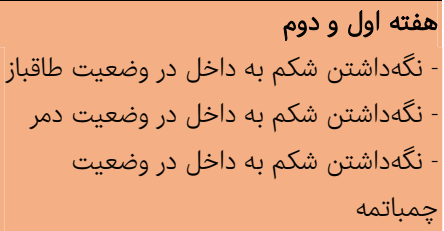 \\
\hline 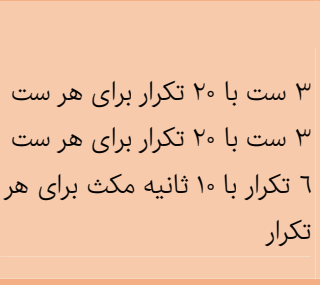 & 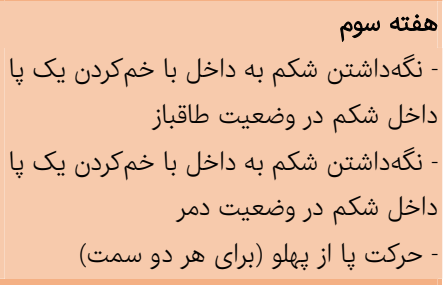 \\
\hline 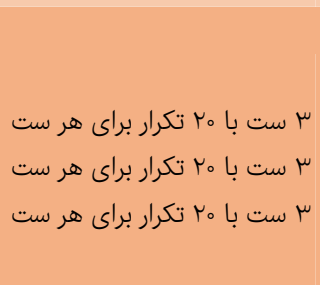 & 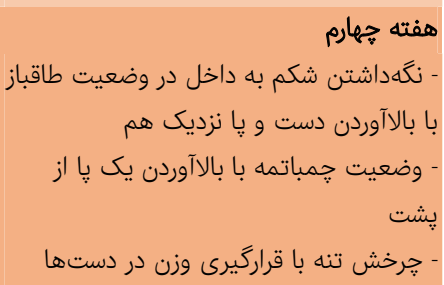 \\
\hline 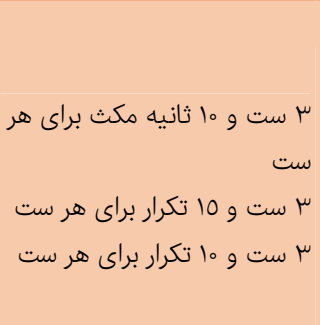 & 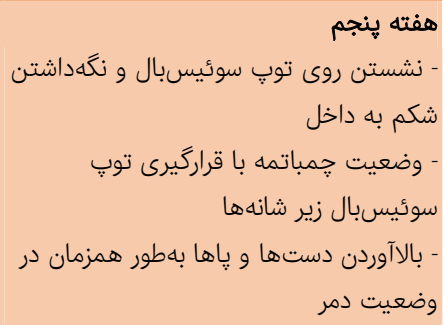 \\
\hline س س ست و 10 ثانيه مكث براى هر و ب تكرار براى هر ست & 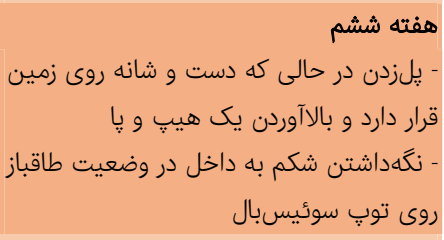 \\
\hline 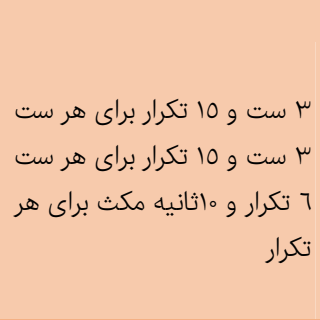 & 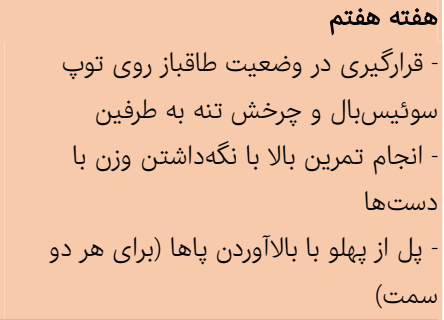 \\
\hline 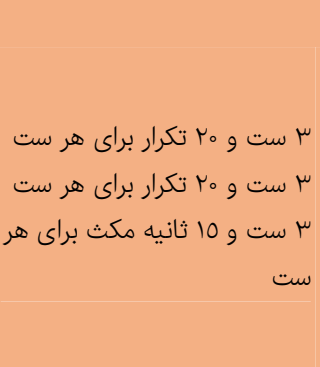 & 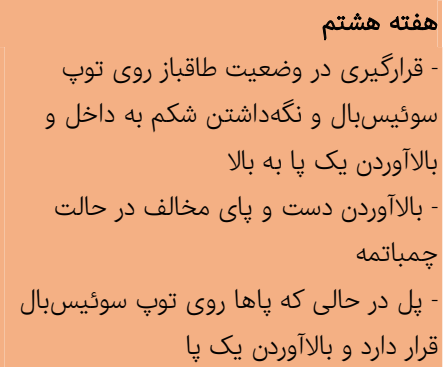 \\
\hline
\end{tabular}

يافتهها

بين دو گروه تجربى و كنترل از نظر متغيرهاى دموكرافيك تفاوت

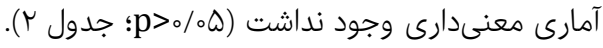

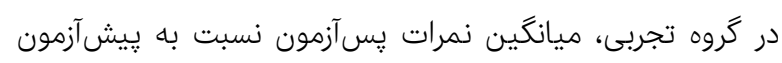

متغيرها، آزمايشكاه دانشكاه فردوسى بود. روند اجراى تحقيق به اين

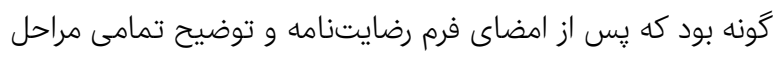

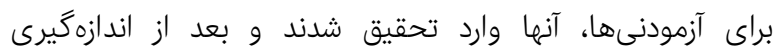

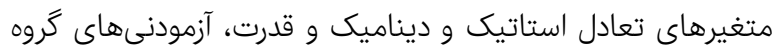

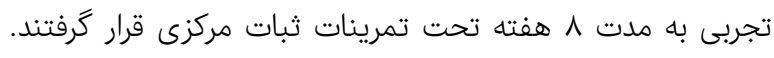

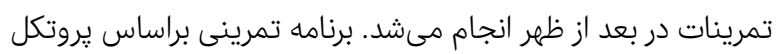

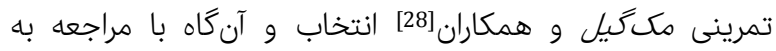

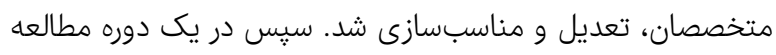

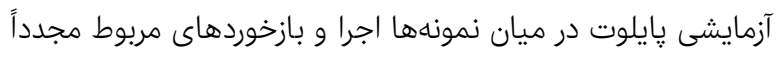
در برنامه تمرينى لحاظ شد.

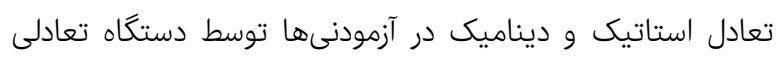

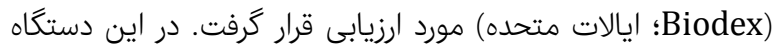

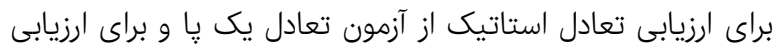

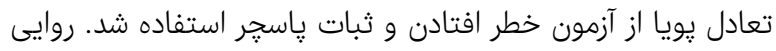

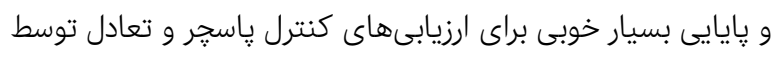

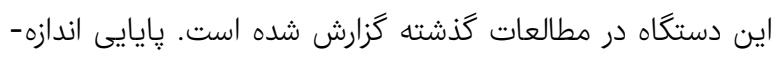

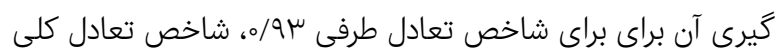

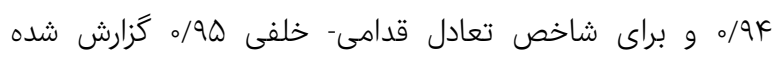

است] [29].

همجنين براى ارزيابى قدرت عضلانى از دستكاه دينامومتر استفاده

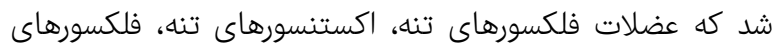

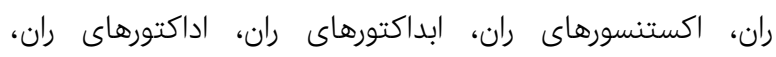
فلكسورها و اكستنسورهاى زانو اندازهكيرى شدند.

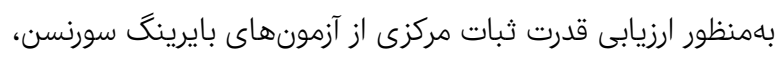

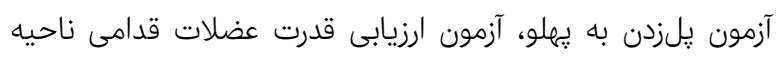
مركزى (آزمون كبرى) و آزمون يلانك استفاده شد.

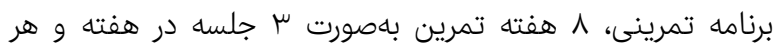

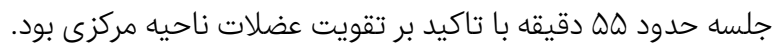

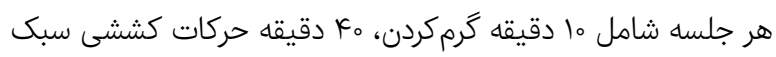

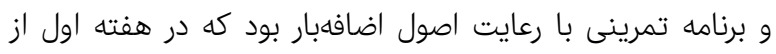

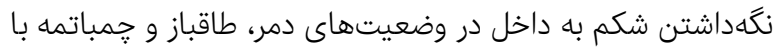

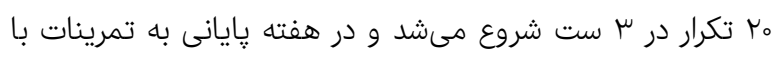

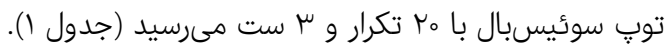

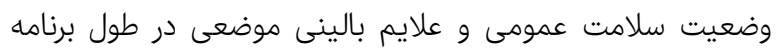

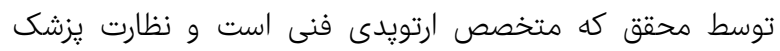

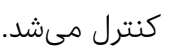
بعد از دوره تمرينى متغيرهاى تحقيق بهمنظور بررسى اثر تاثير

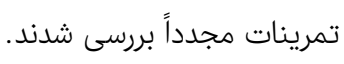

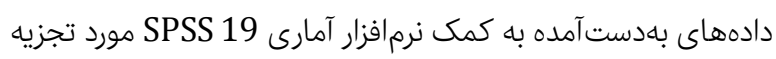

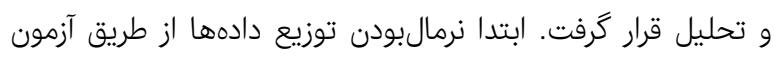

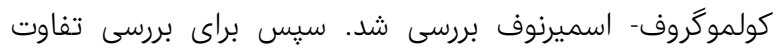

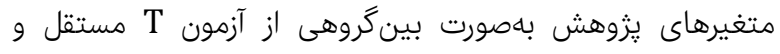
باصورت درون كروهى از آزمون T همبسته استفاده شد. 


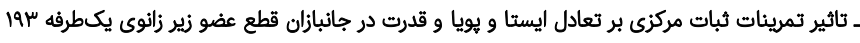

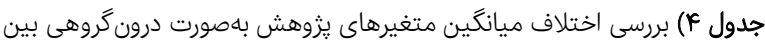

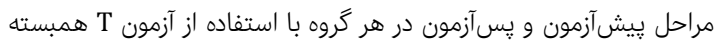

\begin{tabular}{|c|c|c|c|c|}
\hline سطح معنىدارى & مقدار t & درجه آزادى & ميانكين & متغيرها \\
\hline & & & & تعادل ايستا \\
\hline$<0 / 0001$ & $\mid r / 0 \varepsilon$ & IV & $1 / 70$ & گروه تجربى \\
\hline - VO & 每/ & IV & $\circ \%$ & گروه كنترل \\
\hline & & & & خطر افتادن \\
\hline$<0 / 0001$ & $1 \pi / 0 。$ & IV & $1 / \circ V$ & گُروه تجربى \\
\hline$\circ / V I I$ & $\circ / K^{\mu} V$ & IV & $\circ /{ }^{\mu}$ & گروه كنترل \\
\hline & & & & فلكسور ران \\
\hline$<0 / 0001$ & $\Lambda / r q$ & IV & lo/^r & گروه تجربى \\
\hline$ه / \mu \varepsilon$ &.$/ 91$ & IV & $1 / \varepsilon 1$ & گروه كنترل \\
\hline & & & & اكستنسور ران \\
\hline$<0 / 0001$ & $9 / 77$ & IV & $9 / 94$ & گروه تجربى \\
\hline$\circ / 491$ & $1 / \circ V$ & IV & $1 / \mu \varepsilon$ & گروه كنترل \\
\hline & & & & فلكسور زانو \\
\hline$<0 / 0001$ & $7 / 77$ & IV & $\mathrm{V} / \mathrm{A \Lambda}$ & گروه تجربى \\
\hline o/IEr & $1 / 0 \varepsilon$ & IV & $1 / V \varepsilon$ & گروه كنترل \\
\hline & & & & اكستنسور زانو \\
\hline$<0 / 0001$ & $0 / 90$ & IV & १/६१ & گروه تجربى \\
\hline$\circ / \Upsilon \wedge \varepsilon$ & $1 / 1$ & IV & $1 / \varepsilon 7$ & گروه كنترل \\
\hline & & & & ابداكتور ران \\
\hline$<0 / 0001$ & $\mathrm{~V} / \mathrm{rA}$ & IV & $1 / 09$ & گروه تجربى \\
\hline$\circ / \varepsilon \mu \wedge$ & $\circ / \mathrm{V}$ & IV & $\circ / 00$ & گروه كنترل \\
\hline & & & & اداكتور ران \\
\hline$<0 / 0001$ & $10 / 97$ & IV & $q / \gamma_{0}$ & گروه تجربى \\
\hline 。/7人1 & ॰/६) & IV & $\circ / \mu \wedge$ & گروه كنترل \\
\hline & & & & فلكسور تنه \\
\hline$<0 / 0001$ & $10 / 7 \mathrm{~V}$ & IV & IT/ & گروه تجربى \\
\hline -/7rV & ०/६१ & IV & /Or & گروه كنترل \\
\hline & & & & اكستنسور تنه \\
\hline$<0 / 0001$ & $0 / \mu_{0}$ & IV & \urcorner$/ \Upsilon^{\mu} \wedge$ & گروه تجربى \\
\hline . & ॰/AV & IV & $1 / 10$ & كروه كنترل \\
\hline & & & & ثبات مركزى \\
\hline$<0 / 0001$ & $10 / 0 \mu$ & IV & $1 \varepsilon / 10$ & گروه تجربى \\
\hline & 1/OV & IV & $1 / 9 \varepsilon$ & گروه كنترل \\
\hline
\end{tabular}

جدول ه) بررسى اختلاف ميانگين متغيرهاى يزوهش بهصورت بينزروهى بين

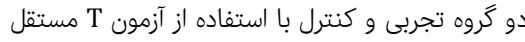

\begin{tabular}{|c|c|c|c|}
\hline مقدار t & درجه آزادى & اختلاف ميانكين & متغيرها \\
\hline $10 / r \varepsilon$ & $\mu \varepsilon$ & $1 / 71$ & تعادل ايستا \\
\hline $9 / 71$ & $\mu \varepsilon$ &.$/ 97$ & خطر افتادن \\
\hline V/a & $\mu \varepsilon$ & lo/AV & فلكسور ران \\
\hline $9 / r r$ & $\mu \varepsilon$ & $10 / 09$ & اكستنسور ران \\
\hline$V / \mu_{\top}$ & $\mu \varepsilon$ & N/OV & فلكسور زانو \\
\hline $7 / 01$ & $\mu \varepsilon$ & $१ / \varepsilon\rceil$ & اكستنسور زانو \\
\hline$\urcorner / \wedge \varepsilon$ & $\mu \varepsilon$ & $9 / r \wedge$ & ابداكتور ران \\
\hline$\Lambda / r q$ & $\mu \varepsilon$ & $\wedge / 7)$ & اداكتور ران \\
\hline q/Ar & $\mu \varepsilon$ & $11 / 9 \varepsilon$ & فلكسور تنه \\
\hline$\Lambda / 7$ 。 & $\mu \varepsilon$ & $10 /{ }^{\mu}$ & ثبات مركزى \\
\hline
\end{tabular}

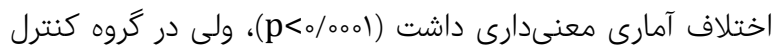

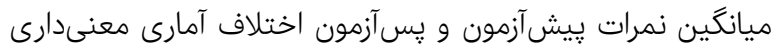

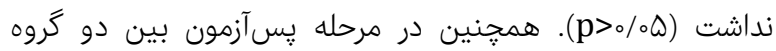

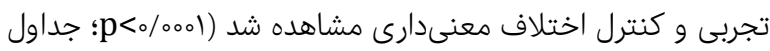

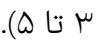

جدول r) مقايسه ميانكين آمارى ويزگى هاى دموگرافيك دو گروه تجربى و كنترل

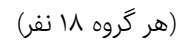

\begin{tabular}{|c|c|c|c|}
\hline معنى دطارى & كروه كنترل & گروه تجربى & ويزُكىهاى دموگرافيك \\
\hline o/TAY & $O r / 7 \Lambda \pm V / I V$ & Or/V $\mu_{ \pm}$ & سن (سال) \\
\hline ०/६0७ & 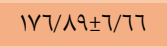 & $\mid V Q / \varepsilon Y \pm V / V Y$ & قد (سانتىمتر) \\
\hline 促 & $\Lambda \mu / .0 \pm I r / \Lambda \varepsilon$ & $\Lambda r / 10 \pm I r / \varepsilon 0$ & وزن (كيلوكرم) \\
\hline$\circ / 0 \circ \mu$ & $\varepsilon V / 0 \circ \pm 9 / 11$ & $\{\Psi / \Lambda \Lambda \pm \| / / \mu \mid$ & درصد جانبازى \\
\hline$\circ / 7 \curlywedge \Lambda$ & $|V / \varepsilon \wedge \pm 0 / q|$ & $\mid V / \Lambda \circ \pm 1 / Y \Lambda$ & استامٍ (سانتىمتر) \\
\hline- & II راست، V جِ & ها راست، 1 هֶٍ & سمت مجروح \\
\hline
\end{tabular}

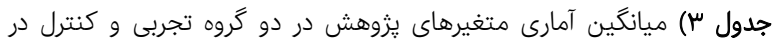

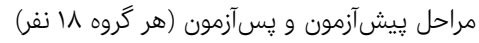

\begin{tabular}{|c|c|c|}
\hline گروه كنترل & "روه تجربى & متغيرها \\
\hline & & تعادل ايستا \\
\hline$r / \Lambda \circ \pm \circ / r V$ & $r / \Lambda Y_{0} / \mu_{0}$ & يِيش آزمون \\
\hline \multirow[t]{2}{*}{$\Gamma / \Lambda \mu_{ \pm 0} / \mu \mu \mu$} & $1 / Y Y \pm 0 / Y q$ & يس آزمون \\
\hline & & خطر افتادن \\
\hline 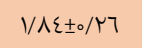 & $1 / ৭ 9 \pm 0 / \Upsilon 7$ & بيشآزمون \\
\hline \multirow{2}{*}{$\mathrm{V} / \Lambda \Lambda \pm 0 / \mu \mathrm{I}$} & 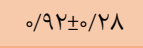 & يس آزمون \\
\hline & & فلكسور ران \\
\hline$r \mu / ৭ ৭ \pm 0 / \mu \mu$ & 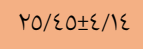 & بِيش آزمون \\
\hline \multirow[t]{2}{*}{$\mathrm{ro} / \varepsilon_{0} \pm \varepsilon / 70$} & $\mu\rceil / r \Lambda \pm \mu / \varepsilon q$ & يس آزمون \\
\hline & & اكستنسور ران \\
\hline $19 / \Gamma \varepsilon \pm \psi / \Lambda 1$ & $|N / 07 \pm \varepsilon / 0|$ & يِيشآزمون \\
\hline \multirow[t]{2}{*}{$\mid V / Q_{\circ} \pm \mu / \mu \wedge$} & $r N / \varepsilon q \pm \mu / 0$ 。 & يس آزمون \\
\hline & & فلكسور زانو \\
\hline سר/ר & $M I / T \circ \pm \varepsilon / N$ & يِيشآزمون \\
\hline \multirow[t]{2}{*}{ ro/Ol } & $r q / \circ q \pm \varepsilon / \wedge \Lambda$ & يس آزمون \\
\hline & & اكستنسور زانو \\
\hline $19 / 0 \varepsilon \pm \mu / \mu r$ & $\mathrm{IV} / 00 \pm \mu / \Lambda \mathrm{V}$ & ييشآزمون \\
\hline \multirow[t]{2}{*}{$\mid V / O V \pm \varepsilon / M \Lambda$} & $r V / 0 \varepsilon \pm \varepsilon / 01$ & يس آزمون \\
\hline & & ابداكتور ران \\
\hline $1 \varepsilon / V \mu_{ \pm} r / /_{0}$ & $\mid \varepsilon / \wedge\rceil \pm 1 / \nearrow_{\circ}$ & يِيش آزمون \\
\hline \multirow[t]{2}{*}{$|\varepsilon / \Lambda \Lambda \pm \mu / 0|$} & $r \mu / \varepsilon 7 \pm \varepsilon / q_{0}$ & يس آزمون \\
\hline & & اداكتور ران \\
\hline$r_{0} / V_{ \pm} \pm \mu^{\prime} / \mu_{0}$ & 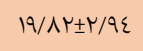 & يِيش آزمون \\
\hline \multirow[t]{2}{*}{$r_{0} / \varepsilon 1 \pm \mu / 0 q$} & $r q /{ }^{\circ} \mu_{ \pm} r / 0 \varepsilon$ & يس آزمون \\
\hline & & فلكسور تنه \\
\hline$|N / r r \pm \mu / q|$ & $\mid V / r \Lambda \pm r / \circ r$ & يِيش آزمون \\
\hline \multirow[t]{2}{*}{$1 V / 79 \pm \mu / 10$} & $r q /\urcorner^{\mu} \pm \varepsilon / \circ \vee$ & يس آزمون \\
\hline & & اكستنسور تنه \\
\hline $\mid r / r V \pm r / q r$ & & پِيش آزمون \\
\hline \multirow[t]{2}{*}{$\mid \mu / 0 \mu_{ \pm} \pm \varepsilon / \mu \mu$} & $r_{0} / Y_{ \pm} \pm / 0 T$ & يس آزمون \\
\hline & & ثبات مركزى \\
\hline$\varepsilon_{0} / 19 \pm \mu / V_{0}$ & $\mu q / / r \pm \varepsilon / \varepsilon 7$ & يِيش آزمون \\
\hline 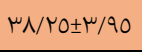 & 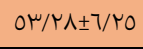 & يس آزمون \\
\hline
\end{tabular}


وضعيت بهتر و كاهش جابهجايى مركز ثقل بر سطح اتكا باعث

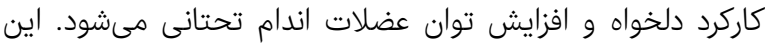

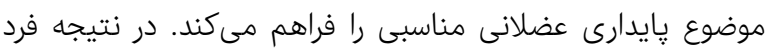

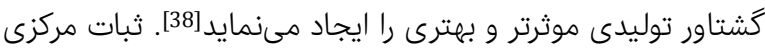

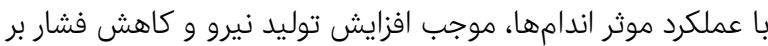

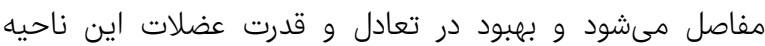
مىتواند بهدليل بهبود در سيستم عصبى- عضلانى و كاهش داه جابهجايى مركز ثقل و بهبود تعادل باشد [4-4139].

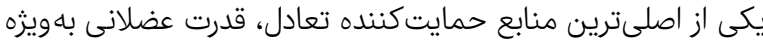

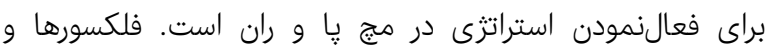

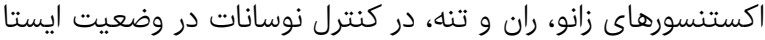

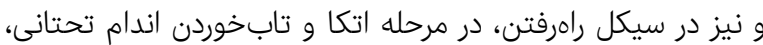

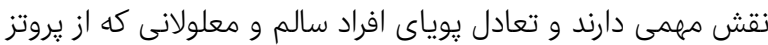

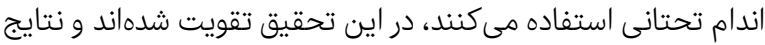

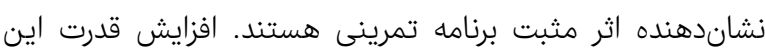
عضلات مىتواند بر متغيرهاى تعادل آزمودنى موثر بوده باشد. آيتار

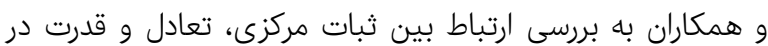

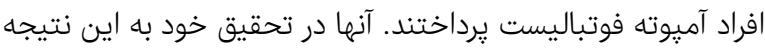
رسيدند كه ارتباط معنىدارى بين قدرت و ثبات مركزى وجود دارد بهصورتى كه با افزايش قدرت (فلكسور تننه) ثبات مركزى افزايش

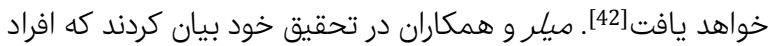

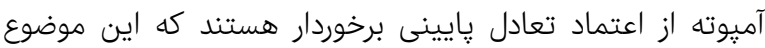

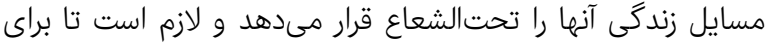

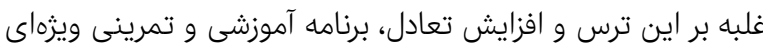
را براى آنان طراحى و اجرا كرد[43]. از طرفى بهبود و افزايش قدرت و افزايش ثبات همراه بران باهر كاهش درد

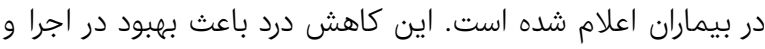

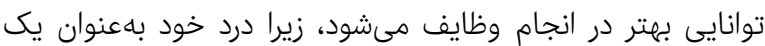

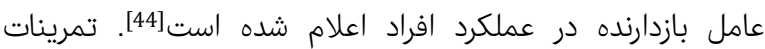
ثباتدهنده موجب اصلاح الخوهاى حركتى غلط شده و اين بهبودي آندان

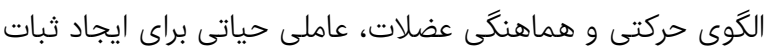
بهتر و حفظ راستاى تنه مى شود [20].

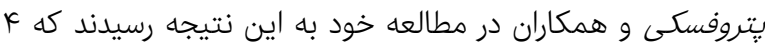

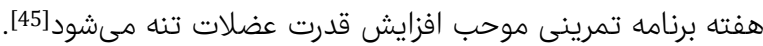

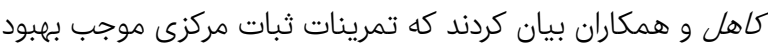

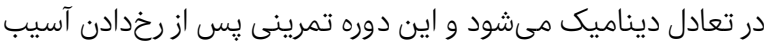

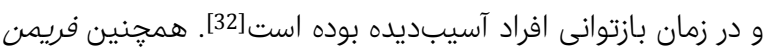

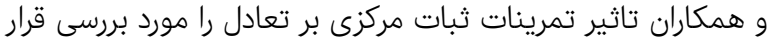

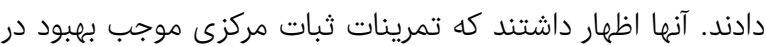

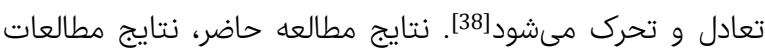

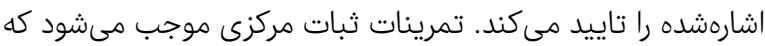
قسمت مركزى از ثبات ساختارى بيشترى برخوردار باشد [46ـات. افراد

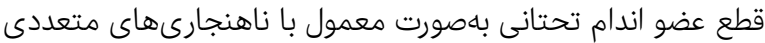

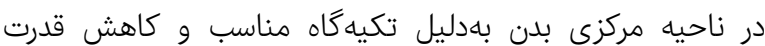

نتايج نشان داد كه تمرينات ثبات مركزى بر تعادل ايستا و يويا و

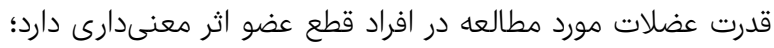
متغيرهاى مورد مطالعه شامل تعادل ايستا و يويا و قدرت عضلات مضات

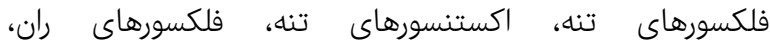
اكستنسورهاى ران، ابداكتورهاى ران، اداكتورهاى ران، فلكسورها و

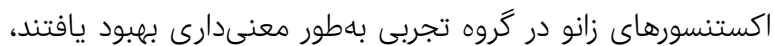
در حالى كه هيج تغييرى در گروه كنترل در اين تحقيق ديده نشاند.

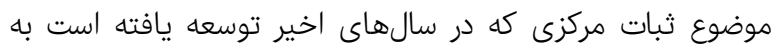

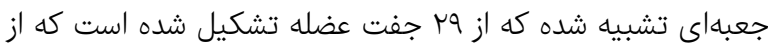

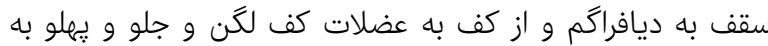
عضلات راست شكمى و مورب داخلى و خارجى و از سطح بشّتى بـ به

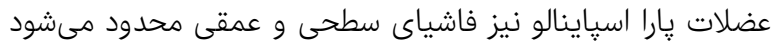

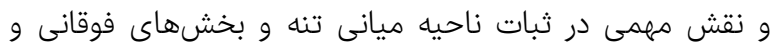

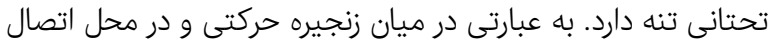

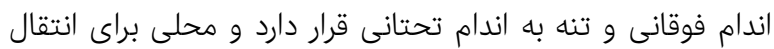

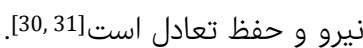

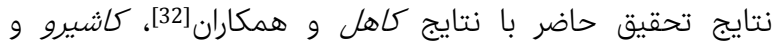

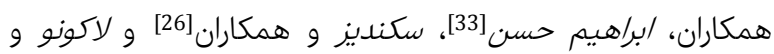
همكاران [34] همخوانى دارد. با وجود آن كه بسيارى از از نمونهها در

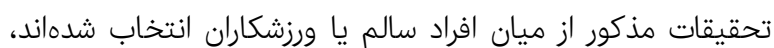

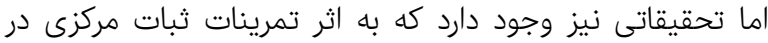

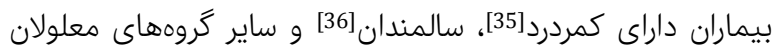

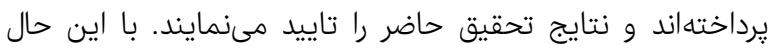

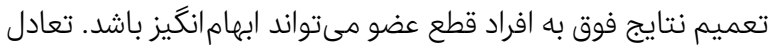

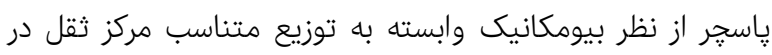
محدوده سطح اتكا است. ازدستدادن بخشى از بدن و بلهويزه اندام تحتانى كه علاوه بر كاهش

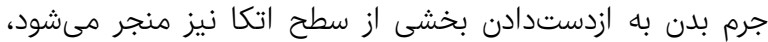

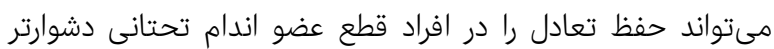

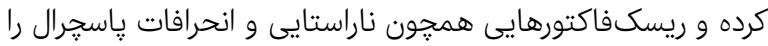

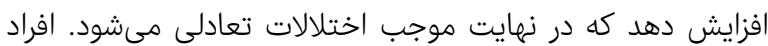

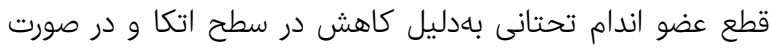

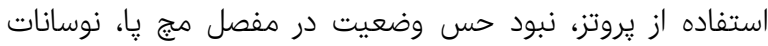

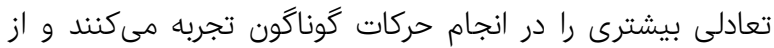

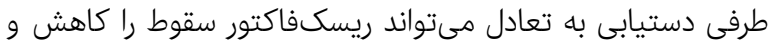
اطمينان از انجام فعاليتهاى حركتى را افزايش دهان

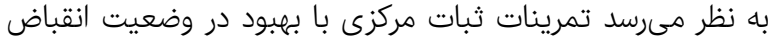

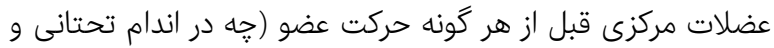

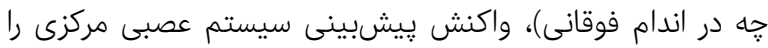

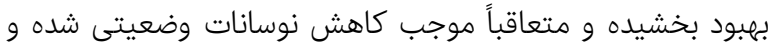

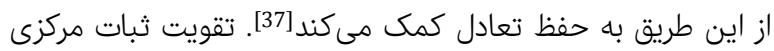
جابهايى خط ثقل را در سطح اتكا كاهش مىدهد كه كاين اين موضوع

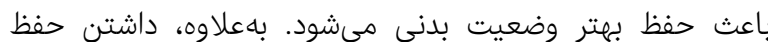


19D تاثير تمرينات ثبات مركزى بر تعادل ايستا و يويا و قدرت در جانبازان قطع عضو زير زانوى يكطرفه

Volumes 4. 3rd Edition. New Delhi: Jaypee Brothers Medical Publishers; 2016. p. 3497-502.

2- Fuenzalida Squella SA, Kannenberg A, Brandão Benetti $\hat{A}$. Enhancement of a prosthetic knee with a microprocessor-controlled gait phase switch reduces falls and improves balance confidence and gait speed in community ambulators with unilateral transfemoral amputation. Prosthet Orthot Int. 2018;42(2):228-35.

3- Seppala LJ, Wermelink AMAT, de Vries M, Ploegmakers KJ, van de Glind EMM, Daams JG, et al. Fall-risk-increasing drugs: a systematic review and meta-analysis: II. Psychotropics. J Am Med Dir Assoc. 2018;19(4):371.e117.

4- Gadelha AB, Neri SGR, Oliveira RJ, Bottaro M, David AC, Vainshelboim B, et al. Severity of sarcopenia is associated with postural balance and risk of falls in communitydwelling older women. Exp Aging Res. 2018;44(3):25869.

5- Steinberg N, Gottlieb A, Siev-Ner I, Plotnik M. Fall incidence and associated risk factors among people with a lower limb amputation during various stages of recovery-a systematic review. Disabil Rehabil. 2019;41(15):1778-87.

6- Geurts AC, Mulder TW, Nienhuis B, Rijken RA. Dual-task assessment of reorganization of postural control in persons with lower limb amputation. Arch Phys Med Rehabil. 1991;72(13):1059-64.

7- Melzer I, Elbar 0, Tsedek I, Oddsson LIE. A water-based training program that include perturbation exercises to improve stepping responses in older adults: study protocol for a randomized controlled cross-over trial. BMC Geriatr. 2008;8(1):19.

8- Geurts ACH, Mulder TW. Reorganisation of postural control following lower limb amputation: theoretical considerations and implications for rehabilitation. Physiother Theory Pract. 1992;8(3):145-57.

9- Johansson J, Nordström A, Nordström P. Greater fall risk in elderly women than in men is associated with increased gait variability during multitasking. J Am Med Dir Assoc. 2016;17(6):535-40.

10- Miller WC, Deathe AB, Speechley M, Koval J. The influence of falling, fear of falling, and balance confidence on prosthetic mobility and social activity among individuals with a lower extremity amputation. Arch Phys Med Rehabil. 2001;82(9):1238-44.

11- Miller WC, Deathe AB. A prospective study examining balance confidence among individuals with lower limb amputation. Disabil Rehabil. 2004;26(14-15):875-81.

12- Feick E, Hamilton PR, Luis M, Corbin M, Salback NM, Torres-Moreno R, et al. A pilot study examining measures of balance and mobility in children with unilateral lowerlimb amputation. Prosthet Orthot Int. 2016;40(1):65-74. 13- Silver-Thorn MB, Kempfer J, Schnorenberg AJ, Slavens BA. Use of a dynamic balance system to quantify postural steadiness and stability of individuals with lower-limb amputation: a pilot study. J Prosthet Orthot. 2017.

14- Hof AL, van Bockel RM, Schoppen T, Postema K. Control of lateral balance in walking: experimental findings in normal subjects and above-knee amputees. Gait Posture. 2007;25(2):250-8.

15- Buckley JG, O'Driscoll D, Bennett SJ. Postural sway and active balance performance in highly active lower-limb amputees. Am J Phys Med Rehabil. 2002;81(1):13-20.

16- Vrieling AH, Van Keeken HG, Schoppen T, Otten E, Hof $\mathrm{AL}$, Halbertsma JP, et al. Balance control on a moving platform in unilateral lower limb amputees. Gait Posture. 2008;28(2):222-8.

$$
\begin{aligned}
& \text { عضلانى در يك طرف روبهرو هستند[9] ,5]. اين تمرينات علاوه بر }
\end{aligned}
$$

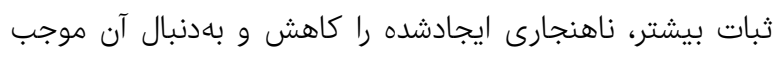

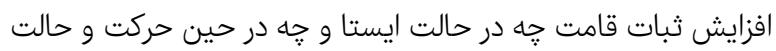

$$
\begin{aligned}
& \text { يويا مىشود [13]. }
\end{aligned}
$$

از محدوديتهاى قابل كنترل تحقيق مىتوان به جنسيت، سن،

محدوديت قطع عضو و حجم و شدت برنامه تمرينى و از

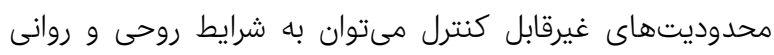
آزمودنىها، تغذيه و فعاليتهاى روزانه افراد اشاره كرد.

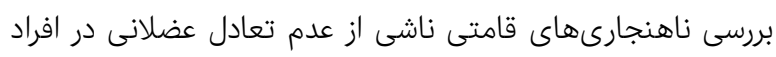

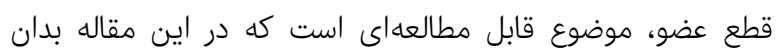

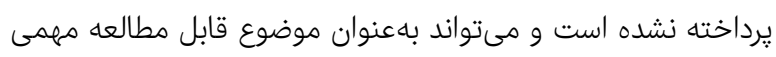

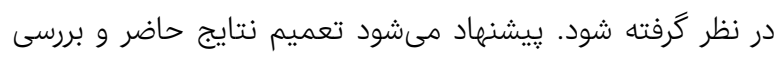

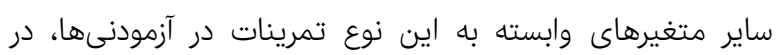
تحقيقات آتى مورد بررسى دقيقتر قرار گيرد.

نتيجه

تمرينات ثبات مركزى در جانبازان قطع عضو زير زانوى يكنطرفه

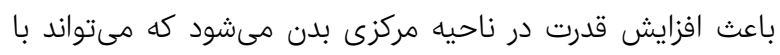
كاهش نوسانات مركز ثقل بدن و كاهش ترس از سقوط دريه مركزي بلد مر افراد قطع

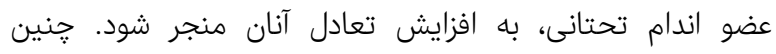

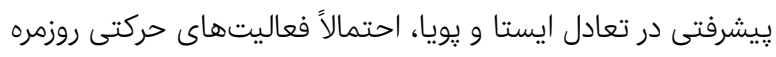

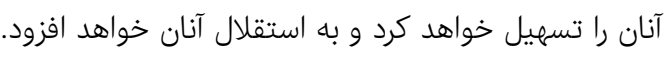

تشكر و قدردانى: تحقيق حاضر بهعنوان بخشى از رساله دكتراى

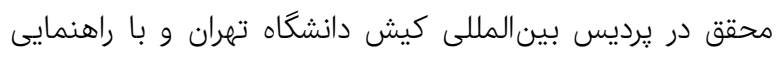

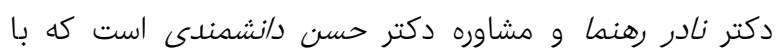

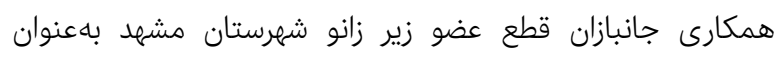

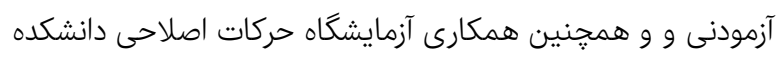

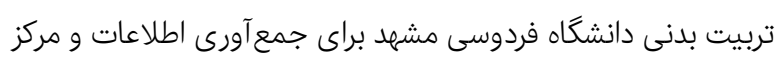

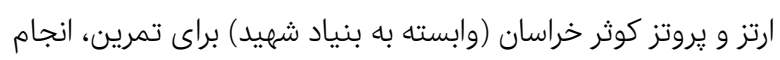

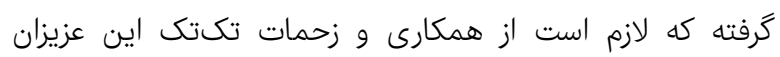
قدردانى و تشكر شود. تاييديه اخلاقى: تمامى شركت كنندكان در يُزوهش، فرم رضايتنامه را امضا كردند. تعارض منافع: هيج گونه تعارض منافعى وجود ندارد.

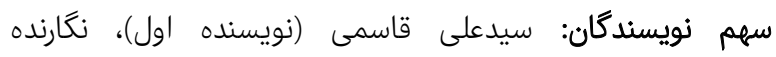

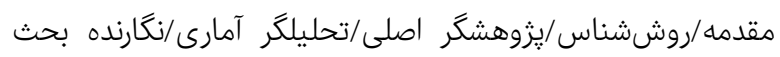

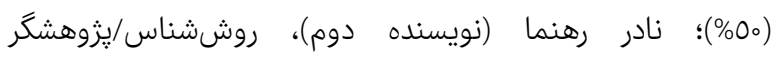

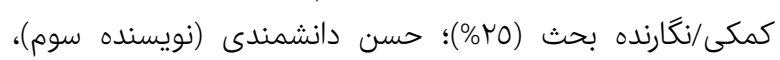

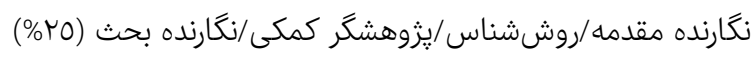
منابع مالى: تحقيق حاضر بخشى از رساله دكتراى محقق بوده استراست

$$
\text { منابع }
$$

1- Naik N. Rehabilitation of adult upper limb amputee. In: Kulkarni Gs, editor. Textbook of orthopedics \& trauma. 
33- Hassan IHI. The effect of core stability training on dynamic balance and smash stroke performance in badminton players. Int J Sport Sci Phys Educ. 2017;2(3):44-52.

34- Iacono AD, Martone D, Alfieri A, Ayalon M, Buono P. Core Stability Training Program (CSTP) effects on static and dynamic balance abilities. Gazz Med Ital Arch per le Sci Med. 2014;173(4):197-206.

35- Chan EWM, Adnan R, Azmi R. Effectiveness of core stability training and dynamic stretching in rehabilitation of chronic low back pain patient. Malaysian J Move Heal Exerc. 2019;8(1):1-13.

36- Naderi Z, Jalali K. The effect of eight weeks of core stability and Pilates trainings on ankle proprioception, postural control, walking performance, self-efficacy and fear of falling in elderly women. Rep Health Care. 2018;4(3):1-13.

37- Kidgell DJ, Horvath DM, Jackson BM, Seymour PJ. Effect of six weeks of dura disc and mini-trampoline balance training on postural sway in athletes with functional ankle instability. J strength Cond Res. 2007;21(2):466-9.

38- Freeman JA, Gear M, Pauli A, Cowan P, Finnigan C, Hunter $\mathrm{H}$, et al. The effect of core stability training on balance and mobility in ambulant individuals with multiple sclerosis: a multi-centre series of single case studies. Mult Scler. 2010;16(11):1377-84.

39- Oshima Y, Miyamoto T, Tanaka S, Wadazumi T, Kurihara N, Fujimoto S. Relationship between isocapnic buffering and maximal aerobic capacity in athletes. Eur J Appl Physiol Occup Physiol. 1997;76(5):409-14.

40- Lederman E. The myth of core stability. J Bodyw Mov Ther. 2010;14(1):84-98.

41- Carter JM, Beam WC, Mcmahan SG, Barr ML, Brown LE. The effects of stability ball training on spinal stability in sedentary individuals. J Strength Cond Res. 2006;20(2):429-35.

42- Aytar A, Pekyavas NO, Ergun N, Karatas M. Is there a relationship between core stability, balance and strength in amputee soccer players? a pilot study. Prosthet Orthot Int. 2012;36(3):332-8.

43- Miller WC, Speechley M, Deathe AB. Balance confidence among people with lower-limb amputations. Phys Ther. 2002;82(9):856-65.

44- Sartipzadeh M, Moazami M, Mohammadi MR. The effect of core stabilization training on elderly balance and knee pain with knee osteoarthritis. J Paramed Sci Rehabil. 2016;5(3):7-17.

45- Petrofsky JS, Cuneo M, Dial R, Pawley AK, Hill J. Core strengthening and balance in the geriatric population. J Appl Res. 2005;5(3):423-33.

46- Sandrey MA, Mitzel JG. Improvement in dynamic balance and core endurance after a 6-week core-stabilitytraining program in high school track and field athletes. J Sport Rehabil. 2013;22(4):264-71. 17- Leijendekkers RA, van Hinte G, Nijhuis-van der Sanden MW, Staal JB. Gait rehabilitation for a patient with an osseointegrated prosthesis following transfemoral amputation. Physiother Theory Pract. 2017;33(2):14761.

18- Angela MD. The relationship between core stability and athletic performance [Dissertation]. Arcata, California: Humboldt State University; 2010.

19- Willardson JM. Core stability training: applications to sports conditioning programs. J Strength Cond Res. 2007;21(3):979-85.

20- Akuthota V, Nadler SF. Core strengthening. Arch Phys Med Rehabil. 2004;85(3 Suppl 1):S86-92.

21- Kibler WB, Press J, Sciascia A. The role of core stability in athletic function. Sport Med. 2006;36(3):189-98.

22- Schultz DG. Validity of the Schultz Slam Test (SST) as a core power measure in football [Dissertation]. Arcata, California: Humboldt State University; 2012.

23- Fox EE, Hough AD, Creanor S, Gear M, Freeman JA. Effects of pilates-based core stability training in ambulant people with multiple sclerosis: multicenter, assessorblinded, randomized controlled trial. Phys Ther. 2016;96(8):1170-8.

24- Willson JD, Dougherty CP, Ireland ML, Davis IM. Core stability and its relationship to lower extremity function and injury. J Am Acad Orthop Surg. 2005;13(5):316-25.

25- Carpes FP, Reinehr FB, Mota CB. Effects of a program for trunk strength and stability on pain, low back and pelvis kinematics, and body balance: a pilot study. J Bodyw Mov Ther. 2008;12(1):22-30.

26- Sekendiz B, Cug M, Korkusuz F. Effects of Swiss-ball core strength training on strength, endurance, flexibility, and balance in sedentary women. J Strength Cond Res. 2010;24(11):3032-40.

27- Li S, Yin Y, Zhang R, Chen W, Zhang Y. Minimally invasive treatment for fractures of lower extremity amputees using a rapid reductor. Int Orthop. 2019;43(6):1473-8.

28- McGill SM, Childs A, Liebenson C. Endurance times for low back stabilization exercises: clinical targets for testing and training from a normal database. Arch Phys Med Rehabil. 1999;80(8):941-4.

29- Sohbatiha M, Aslankhani MA, Farsi A. The Effect of aquatic and land-based exercises on static and dynamic balance of healthy male older people. Iran J Ageing. 2011;6(20):54-63. [Persian]

30- Faries MD, Greenwood M. Core training: stabilizing the confusion. Strength Cond J. 2007;29(2):10-25.

31- Haruyama K, Kawakami M, Otsuka T. Effect of core stability training on trunk function, standing balance, and mobility in stroke patients: a randomized controlled trial. Neurorehabil Neural Repair. 2017;31(3):240-9.

32- Kahle NL, Gribble PA. Core stability training in dynamic balance testing among young, healthy adults. Athl Train Sport Health Care. 2009;1(2):65-73. 